\title{
Synthesis of Polyesters from Terephthalaldehyde and Isophthalaldehyde through Tishchenko Reaction Catalyzed by the Ethylmagnesium Bromide-(-)-Sparteine Complex and Aluminum Alkoxides
}

\author{
Seong-Ho Choi, Eiji Yashima, and Yoshio Окамото ${ }^{\dagger}$ \\ Department of Applied Chemistry, School of Engineering, Nagoya University, \\ Chikusa-ku, Nagoya 464-01, Japan
}

(Received September 13, 1996)

\begin{abstract}
Terephthalaldehyde (TPA) and isophthalaldehyde (IPA) were polymerized with the ethylmagnesium bromide-(-)-sparteine (EtMgBr-Sp) complex and aluminum alkoxides as catalysts to obtain polyesters through the Tishchenko reaction. The polyester prepared from TPA with the EtMgBr-Sp complex was characterized by $\mathrm{IR}$, FD mass, ${ }^{1} \mathrm{H}$ and ${ }^{13} \mathrm{C}$ NMR spectroscopies, and was found to be a random copolymer composed of oxycarbonyl-1,4-phenylenemethylene and terephthaloyloxymethylene-1,4-phenylenemethyleneoxy units. The polyesters possessed terminal formyl groups and were further polymerized with the EtMgBr-Sp complex. On the basis of the results, a possible mechanism for the polymerization is discussed. KEY WORDS Terephthalaldehyde / Isophthalaldehyde / Tishchenko Reaction / Sparteine / Polyester / Aluminum Alkoxides
\end{abstract}

Condensation reactions of aldehydes to produce esters are known as the Tishchenko reaction, ${ }^{1}$ which are catalyzed by various metal complexes ${ }^{2}$ including aluminum alkoxides, ${ }^{3}$ lanthanoid complexes, ${ }^{4}$ and ruthenium complexes. ${ }^{5}$ The metal complexes may be used as the catalysts for the syntheses of polyesters from dialdehydes such as terephthalaldehyde (TPA) through the Tishchenko reaction. However, a few papers describe the polyester syntheses using the metal complexes. Mitin et al. $^{6}$ and later, Sweeny ${ }^{7}$ reported the polymerization of TPA to polyesters by means of the Tishchenko reaction with aluminum ethoxide and alkylaluminums, respectively. The polyesters were examined by IR, X-ray diffraction patterns, and differential thermal analysis (DSC), and their structures were postulated to be not pure poly(oxycarbonyl-1,4-phenylenemethylene) (1), but a random copolymer composed of oxycarbonyl-1,4phenylenemethylene and terephthaloyloxymethylene1,4-phenylenemethyleneoxy (4-xylyleneterephthalate) units (2). Very recently, Yamamoto and co-workers also prepared polyesters with ruthenium complexes similar in structures to those reported by Sweeny from TPA through the Tishchenko reaction. ${ }^{8}$
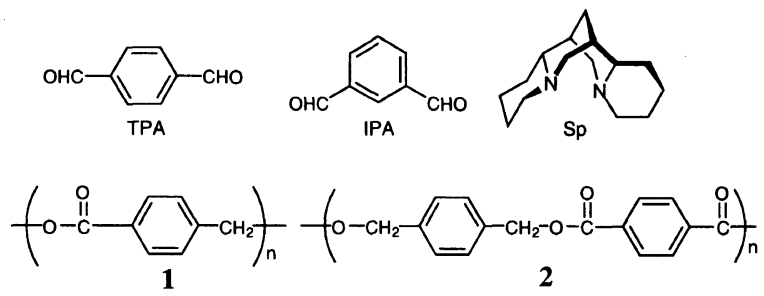

Previously, we found that an optically active poly(3phenylpropanal) with a predominant one-handed helical structure could be obtained by the asymmetric polymerization of 3-phenylpropanal (3-PPA) with the ethylmagnesium bromide- $(-)$-sparteine $(\mathrm{EtMgBr}-\mathrm{Sp})$ complex in toluene at $-78^{\circ} \mathrm{C} .{ }^{9}$ The polymerization was also initiated

\footnotetext{
† To whom correspondence should be addressed.
}

with 3-phenylpropoxymagnesium bromide and terminated by the Tishchenko reaction to afford the polymer having an ester terminal at $\omega$-end. In the polymerization, a large amount of 3-phenylpropyl 3-phenylpropanoate was produced as a side product through the Tishchenko reaction. These results indicate that the $\mathrm{EtMgBr}-\mathrm{Sp}$ complex can be used as a novel catalyst for the enantioselective Tishchenko reaction of racemic aldehydes such as ( \pm )-2-phenylpropanal (2-PPA). Actually, the EtMgBr-Sp complex catalyzed the enantioselective Tishchenko reaction to afford optically active 2-phenylpropyl 2-phenylpropanoate. Enantiomeric excess of optically active 2-phenylpropyl 2-phenylpropanoate obtained achieved up to $65 \% .{ }^{10}$ In both reactions, 3-phenyl- or 2-phenylpropoxymagnesium bromide-Sp complex is a real intermediate and further reacts with 3-PPA or 2-PPA followed by the Tishchenko-type termination again with the aldehydes to afford the optically active poly(3-PPA) having an ester terminal at $\omega$-end and 2-phenylpropyl 2-phenylpropanoate, respectively, as a cyclic mechanism. ${ }^{9,10}$ These results led us to apply our system to prepare polyesters from dialdehydes such as TPA and isophthalaldehyde (IPA) through the Tishchenko reaction. (-)-Sparteine is a commercially available chiral diamine and has been widely used for asymmetric synthesis, ${ }^{11}$ helix-sense-selective polymerization, ${ }^{12}$ and enantiomer-selective polymerization of racemic methacrylates. ${ }^{13}$

In the present study, we performed the polymerization of TPA and IPA with the EtMgBr-Sp complex and aluminum alkoxides through the Tishchenko reaction. The structures of polyesters and the mechanism of the polymerization were elucidated on the basis of IR, 1D and 2D NMR, and FD-mass spectroscopies.

\section{EXPERIMENTAL}

\section{Materials}

TPA, IPA, terephthalic acid, and 4-carboxybenzaldehyde were purchased from Tokyo Kasei and used as 
received. 1,4-Bis(hydroxymethyl)benzene, 4-(chloromethyl)benzoic acid, and $\mathrm{Me}_{3} \mathrm{Al}$ in toluene $(2 \mathrm{M})$ were obtained from Aldrich. $(R)-(+)-1,1^{\prime}-\mathrm{Bi}-2-$ naphthol $\left([\alpha]_{\mathrm{D}}^{25}\right.$ $+32^{\circ}, c 1.5 \mathrm{~g} \mathrm{dl}^{-1}$, tetrahydrofuran (THF)) was obtained from Kankyo Kagaku Center. EtMgBr was prepared by the usual method using magnesium and ethyl bromide in dry ether under nitrogen atmosphere and its concentration was determined to be $0.92 \mathrm{M}$ by acid and base titration. Toluene was purified in the usual manner, mixed with a small amount of butyllithium, and distilled under high vacuum just before use. THF was dried over sodium benzophenone ketyl before distillation and further distilled over $\mathrm{LiAlH}_{4}$ under high vacuum just before use. Dichloromethane and chloroform were dried over $\mathrm{CaH}_{2}$ and distilled under high vacuum just before use. (-)-Sparteine (Sigma) was dried over $\mathrm{CaH}_{2}$ for $2 \mathrm{~h}$ with stirring and distilled under reduced pressure (bp 92.0 $93.5^{\circ} \mathrm{C} / 0.06 \mathrm{mmHg}$ ). Aluminum isopropoxide was from Tokyo Kasei and used as a toluene solution ( $2 \mathrm{M}$ ).

\section{Preparation of Catalysts}

The EtMgBr-Sp complex was prepared by mixing $\mathrm{EtMgBr}$ with 1.2 equivalent (-)-Sp in toluene at room temperature under dry nitrogen, and the concentration of the complex was adjusted to $0.30 \mathrm{M}$. The complex $\left((R)\right.$-BIN-Al) of $(R)-(+)-1,1^{\prime}$-bi-2-naphthol with $\mathrm{Me}_{3} \mathrm{Al}$ was prepared by mixing $(R)-(+)-1,1^{\prime}$-bi-2-naphthol in dry toluene with 1 equivalent $\mathrm{Me}_{3} \mathrm{Al}$ in toluene at room temperature under dry nitrogen. Methane gas was produced immediately. The mixture was stirred for $1 \mathrm{~h}$ at room temperature and used as a catalyst for the polymerization.

\section{Polymerization Procedure}

Polymerization was carried out in a glass ampule under dry nitrogen atmosphere. A typical polymerization procedure is described below. TPA $(1.0 \mathrm{~g}, 7.5 \mathrm{mmol})$ was placed in an ampule, and was dried on a vacuum line. After the ampule was flushed with dry nitrogen, a threeway stopcock was attached to the ampule. Chloroform $(10 \mathrm{ml})$ was then added with a hypodermic syringe. The monomer solution was cooled to $0^{\circ} \mathrm{C}$, and the prescribed initiator solution was added to the mixture to initiate the polymerization with a syringe. After $30 \mathrm{~min}$, the ampule was placed in a water bath at $30^{\circ} \mathrm{C}$ or $50^{\circ} \mathrm{C}$. The molar ratio of monomer to $\mathrm{EtMgBr}$ or aluminum alkoxide was 50 unless otherwise noted. The reaction was terminated with a few drops of methanol containing a small amount of $\mathrm{HCl}$. The polymer was precipitated in a large amount of methanol, separated by centrifugation, and dried in vacuo at $50^{\circ} \mathrm{C}$ for $3 \mathrm{~h}$.

Spectroscopic data of poly(TPA) (run 4 in Table I). IR (KBr): $1717 \mathrm{~cm}^{-1}(\mathrm{C}=\mathrm{O}), 1270,1100 \mathrm{~cm}^{-1}(\mathrm{C}-\mathrm{O})$; ${ }^{1} \mathrm{H}$ and ${ }^{13} \mathrm{C}$ NMR (see Figure 2 (a and b)). Anal. Calcd for $\left(\mathrm{C}_{8} \mathrm{H}_{6} \mathrm{O}_{2}\right)_{n}: \mathrm{C}, 71.63 ; \mathrm{H}, 4.51 \%$. Found: $\mathrm{C}, 69.59 ; \mathrm{H}$, $4.43 \%$.

\section{Preparation of Model Compounds and Polymers}

Poly(terephthaloyloxymethylene-1,4-phenylenemethyleneoxy). To a solution of 1,4-bis(hydroxymethyl)benzene $(1.4 \mathrm{~g}, 10 \mathrm{mmol})$ and triethylamine $(28 \mathrm{mmol})$ in dry dichloromethane $(50 \mathrm{ml})$, terephthaloyl dichloride $(2.0 \mathrm{~g}$, $10 \mathrm{mmol}$ ) was added under nitrogen. After the mixture was stirred at $40^{\circ} \mathrm{C}$ for $3 \mathrm{~h}$, it was cooled to room temperature and poured into methanol $(200 \mathrm{ml})$. The polymer precipitated was separated by centrifugation, washed with methanol, and dried in vacuo at $50^{\circ} \mathrm{C}$ for $3 \mathrm{~h}$. The polymer obtained was not soluble in common organic solvents. The yield of the polymer was $2.6 \mathrm{~g}$ (98\%). IR (KBr): $1717 \mathrm{~cm}^{-1}(\mathrm{C}=\mathrm{O}), 1272,1102 \mathrm{~cm}^{-1}$ (C-O).

Poly(oxycarbonyl-1,4-phenylenemethylene) (1). This polymer was prepared according to the reported procedure $^{14}$ by the polymerization of 4-(chloromethyl)benzoic acid in the presence of triethylamine in THF under reflux. IR (KBr): $1717 \mathrm{~cm}^{-1}(\mathrm{C}=\mathrm{O}), 1272,1102 \mathrm{~cm}^{-1}$ (C-O).

Model compounds, dimethyl terephthalate (3), 1,4bis(acetyloxymethyl)benzene (4), and 4-(hydroxymethyl)benzoic acid (5) were prepared by usual methods or according to the reported procedure.

(3): $\mathrm{mp} 140-142^{\circ} \mathrm{C} ;{ }^{1} \mathrm{H} \mathrm{NMR}\left(\mathrm{CDCl}_{3}\right): \delta 3.95(\mathrm{~s}, 3 \mathrm{H}$, $\left.-\mathrm{CH}_{3}\right), \delta 8.10(\mathrm{~s}, 4 \mathrm{H},-\mathrm{Ph}) ;{ }^{13} \mathrm{C} \mathrm{NMR}\left(\mathrm{CDCl}_{3}\right): 166.29$, 133.92, 129.54, 52.35; IR (KBr): $1721 \mathrm{~cm}^{-1}(\mathrm{C}=\mathrm{O})$; EI-MS: $194\left(\mathrm{M}^{+}\right)$.

(4): $\mathrm{mp} 42-43^{\circ} \mathrm{C} ;{ }^{1} \mathrm{H}$ NMR $\left(\mathrm{CDCl}_{3}\right) \delta 2.10(\mathrm{~s}, 3 \mathrm{H}$, $\left.-\mathrm{CH}_{3}\right), \delta 5.10\left(\mathrm{~s}, 4 \mathrm{H},-\mathrm{CH}_{2}-\mathrm{Ph}\right), \delta 8.10(\mathrm{~s}, 4 \mathrm{H},-\mathrm{Ph})$; ${ }^{13} \mathrm{C} \mathrm{NMR}\left(\mathrm{CDCl}_{3}\right)$ 170.85, 136.04, 128.45, 65.85, 20.89; IR (KBr) $1723 \mathrm{~cm}^{-1}(\mathrm{C}=\mathrm{O})$; EI-MS: $222\left(\mathrm{M}^{+}\right)$.

(5): mp $175-177^{\circ} \mathrm{C}$ (lit. ${ }^{15} 174-180^{\circ} \mathrm{C}$ ); ${ }^{1} \mathrm{H}$ NMR (dimethyl sulfoxide (DMSO)- $d_{6}$ ): $\delta 3.38\left(\mathrm{~s}, 2 \mathrm{H},-\mathrm{CH}_{2} \mathrm{OH}\right.$ ), $\delta 5.20$ (s (broad), $1 \mathrm{H},-\mathrm{OH}), \delta 7.44-7.92(\mathrm{~d},-\mathrm{Ph}, 4 \mathrm{H})$; ${ }^{13}$ C NMR (DMSO- $d_{6}$ ): 167.59, 148.04, 129.46, 129.36, 126.46; IR (KBr): $3420(-\mathrm{OH}), 1720 \mathrm{~cm}^{-1}(\mathrm{C}=\mathrm{O})$; EIMS: $152\left(\mathrm{M}^{+}\right)$.

\section{Alkaline Hydrolysis of the Polyester Obtained with the Et $M g B r-S p$ Complex}

Poly(TPA) $(0.50 \mathrm{~g}$, run 4 in Table I) was dispersed in ethanol $(15 \mathrm{ml})$ containing $\mathrm{KOH}(1 \mathrm{~g})$ at room temperature. After $6 \mathrm{~h}$ stirring, the solution was poured into $\mathrm{H}_{2} \mathrm{O}$, and then extracted with ether. The ether solution was dried over $\mathrm{Mg}_{2} \mathrm{SO}_{4}$, and the ether was removed by evaporation, yielding oily residues $(c a .0 .06 \mathrm{~g}, c a .10 \%$ yield based on the poly(TPA)). The aqueous layer was acidified with $1 N \mathrm{HCl}$ solution and the mixture was extracted with ether. The ether solution was dried over $\mathrm{Mg}_{2} \mathrm{SO}_{4}$, and the ether was removed by evaporation, giving a crystalline residue (ca. $0.5 \mathrm{~g}, c a .88 \%$ ). Each product obtained from the ether layer and aqueous layer was dissolved in DMSO- $d_{6}$, and ${ }^{1} \mathrm{H},{ }^{13} \mathrm{C} \mathrm{NMR}$, and electron impact (EI) mass spectra were measured. The data are given in Figure 3.

\section{Measurements}

One dimensional ${ }^{1} \mathrm{H}$ and ${ }^{13} \mathrm{C}$ NMR and two dimensional COSY spectra were taken on a Varian VXR$500 \mathrm{~S}\left(500 \mathrm{MHz}\right.$ for ${ }^{1} \mathrm{H}$ and $125 \mathrm{MHz}$ for ${ }^{13} \mathrm{C}$ ) or a Varian GEMINI $2000\left(400 \mathrm{MHz}\right.$ for ${ }^{1} \mathrm{H}$ and $100 \mathrm{MHz}$ for $\left.{ }^{13} \mathrm{C}\right)$ spectrometer in $\mathrm{CDCl}_{3}$ or DMSO- $d_{6}$. TMS was the internal standard. Field desorption (FD) and EI mass spectra were recorded on a JEOL JMS-AX505HA spectrometer. Thermogravimetric analysis (TGA) was made on a Regaku DSC-8230 apparatus with heating rate $10^{\circ} \mathrm{C} \mathrm{min}^{-1}$ in the temperature range of $30-500^{\circ} \mathrm{C}$. IR spectra were recorded using a JASCO Fourier Trans- 
form IR-7000 spectrophotometer with a JASCO PTL396 data processor. Gel permeation chromatography (GPC) was performed using a JASCO 880-PU chromatography equipped with a UV-visible $(254 \mathrm{~nm}$; JASCO 875-UV) detector. GPC columns, Shodex KF-802.5 $(30 \times 0.72$ (i.d.) $\mathrm{cm})$ and AC-80 $(50 \times 0.72$ (i.d.) $\mathrm{cm})$ were connected in series and chloroform was used as the eluent at a flow rate of $1.0 \mathrm{ml} \mathrm{min}{ }^{-1}$. The molecular weight calibration curve was obtained with standard polystyrenes (Tosoh).

\section{RESULTS AND DISCUSSION}

\section{Polymerization of TPA and IPA with the EtMgBr-Sp Complex and Structure of Polymers}

Table I shows the results of polymerization of TPA and IPA with the EtMgBr-Sp complex under various reactions conditions together with those of polymerization by uncomplexed EtMgBr in chloroform. In THF at $0^{\circ} \mathrm{C}$, methanol-insoluble polymers were not obtained with the EtMgBr-Sp complex. However, poly(TPA) was obtained in a good yield in chloroform and dichloromethane at $0^{\circ} \mathrm{C}$ or at higher temperatures, although the number-average molecular weight $\left(M_{n}\right)$ of poly(TPA)s was relatively low $(1500-2800)$ compared with reported values $(900-5200)^{8}$ probably because the polymers precipitated during the polymerization in the solvents used. The poly(TPA)s obtained with the EtMgBr-Sp complex were soluble in chloroform and dichloromethane, but insoluble in benzene, toluene, and THF. However, poly(TPA)s precipitated during the polymerization even in chloroform. This may be due to aggregation of the active species of the polymer chain ends, since the polymers were soluble in chloroform after isolation. The molecular weight of poly(TPA)s increased when a mixture of chloroform and THF was used as the solvent (run 9-12 in Table I). No polymer was obtained using uncomplexed $\mathrm{EtMgBr}$ alone as the catalyst in chloroform (run 6 in Table I). Moreover, polymeric products were not produced by polymerization of TPA with the EtMgBr- $(+)-(2 S, 3 S)-2,3$-dimethoxy-1,4-bis(dimethylamino)butane or $-N, N, N^{\prime}, N^{\prime}$-tetramethylethylene- diamine complexe in chloroform at $30^{\circ} \mathrm{C}$. These results clearly indicate that sparteine is essential and very specific for the production of poly(TPA) ${ }^{9,10}$ Polymerizability of IPA with the EtMgBr-Sp complex in dichloromethane at $30^{\circ} \mathrm{C}$ was lower than that of TPA and a very small amount of polymer was obtained (runs 15 and 16 in Table I).

Figure 1 shows the IR spectrum of poly(TPA) obtained with the EtMgBr-Sp complex in chloroform at $30^{\circ} \mathrm{C}$ for $28 \mathrm{~h}$ (run 4 in Table I). The spectrum exhibited a characteristic absorption at 1717, and 1270 and 1100 $\mathrm{cm}^{-1}$ due to $\mathrm{C}=\mathrm{O}$ and $\mathrm{C}-\mathrm{O}$ stretchings, respectively. The IR spectral pattern of the polymer closely resembles the IR spectra of poly(oxycarbonyl-1,4-phenylenemethylene) (1) prepared from the polymerization of 4-bromomethylbenzoic acid by Pinkus, et $a l .{ }^{14}$ and polyesters prepared from TPA with alkylaluminums by Sweeny. ${ }^{7}$ This indicates that the poly(TPA) obtained with the EtMgBr-Sp complex is a polyester. The polyester appears to be produced by the Tishchenko reaction which can catalytically convert formyl groups into ester groups. ${ }^{9,10}$ The EtMgBr-Sp complex is found to be a novel catalyst to the polyester synthesis from a dialdehyde.

The ${ }^{1} \mathrm{H}$ (a) and ${ }^{13} \mathrm{C}$ (b) NMR spectra of poly(TPA)

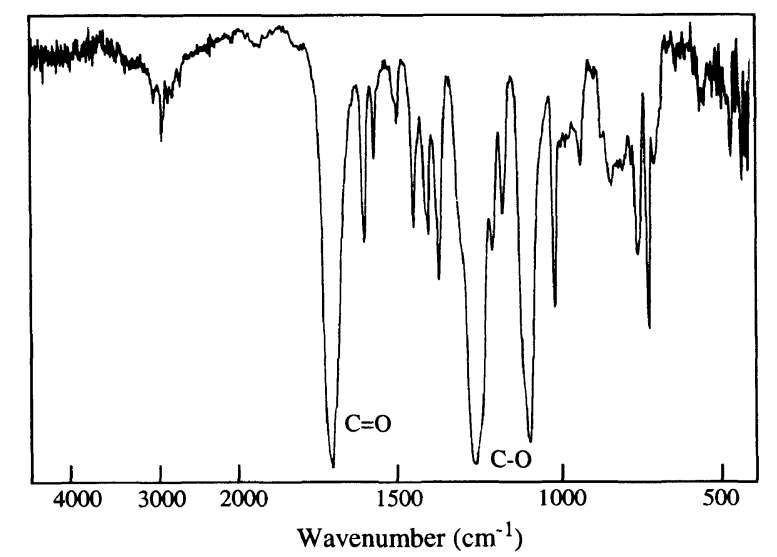

Figure 1. IR spectrum of poly(TPA) (run 4 in Table I) obtained with the $\mathrm{EtMgBr}-\mathrm{Sp}$ complex.

Table I. Polymerization of TPA and IPA with the EtMgBr-Sp complex under various reaction conditions ${ }^{\mathrm{a}}$

\begin{tabular}{|c|c|c|c|c|c|c|c|}
\hline Run & Solvent $^{b}$ & Catalyst $/ \mathrm{mol} \%$ & Temp $/{ }^{\circ} \mathrm{C}$ & Time $/ \mathrm{h}$ & Yield $/ \%^{c}$ & $\bar{M}_{n} \times 10^{-3^{d}}$ & $\bar{M}_{w} / \bar{M}_{n}^{\mathrm{d}}$ \\
\hline 1 & THF & 2 & 0 & 28 & 0 & - & - \\
\hline 2 & THF & 2 & 30 & 28 & 7.8 & 1.5 & 1.28 \\
\hline 3 & $\mathrm{CHCl}_{3}$ & 2 & 0 & 28 & 67.0 & 1.9 & 1.33 \\
\hline 4 & $\mathrm{CHCl}_{3}$ & 2 & $30^{\mathrm{e}}$ & 28 & 79.5 & 2.0 & 1.28 \\
\hline 5 & $\mathrm{CHCl}_{3}$ & 4 & $50^{\mathrm{e}}$ & 18 & 53.0 & 2.0 & 1.26 \\
\hline $6^{\mathrm{f}}$ & $\mathrm{CHCl}_{3}$ & 2 & $30^{\mathrm{e}}$ & 118 & 0 & - & - \\
\hline 7 & $\mathrm{CH}_{2} \mathrm{Cl}_{2}$ & 2 & $30^{\mathrm{e}}$ & 18 & 53.1 & 2.1 & 1.21 \\
\hline 8 & $\mathrm{CH}_{2} \mathrm{Cl}_{2}$ & 4 & $30^{\mathrm{e}}$ & 18 & 65.3 & 2.1 & 1.23 \\
\hline 9 & A & 2 & $25^{\mathrm{e}}$ & 18 & 9.2 & 2.5 & 1.28 \\
\hline 10 & A & 2 & $50^{\mathrm{e}}$ & 18 & 74.3 & 2.6 & 1.25 \\
\hline 11 & A & 2 & $50^{\mathrm{g}}$ & 18 & 71.0 & 2.7 & 1.23 \\
\hline 12 & A & 2 & $60^{\mathrm{e}}$ & 118 & 82.3 & 2.6 & 1.46 \\
\hline 13 & B & 2 & $40^{\mathrm{e}}$ & 118 & 52.8 & 1.8 & 1.33 \\
\hline 14 & $\mathrm{C}$ & 2 & $60^{\mathrm{e}}$ & 118 & 85.0 & 2.3 & 1.40 \\
\hline $15^{\mathrm{h}}$ & $\mathrm{CH}_{2} \mathrm{Cl}_{2}$ & 2 & $30^{\mathrm{e}}$ & 18 & 1 & 1.6 & 1.53 \\
\hline $16^{h}$ & $\mathrm{CH}_{2} \mathrm{Cl}_{2}$ & 4 & $30^{\mathrm{e}}$ & 18 & 4.2 & 2.8 & 1.10 \\
\hline
\end{tabular}

${ }^{\text {a }}$ TPA $(1.0 \mathrm{~g}, 7.5 \mathrm{mmol}),[\mathrm{Sp}] /[\mathrm{EtMgBr}]=1.2$, solvent $10 \mathrm{ml} .{ }^{\mathrm{b}} \mathrm{A}=\mathrm{CHCl}_{3}-\mathrm{THF}(7: 3), \mathrm{B}=\mathrm{CH}_{2} \mathrm{Cl}_{2}-\mathrm{THF}(9: 1), \mathrm{C}=\mathrm{CHCl}_{3}-\mathrm{THF}(9: 1)$. ${ }^{\mathrm{c}} \mathrm{MeOH}$-insoluble fraction. ${ }^{\mathrm{d}}$ Estimated by GPC (polystyrene standards). ${ }^{\mathrm{e}}$ Initiation was performed at $0^{\circ} \mathrm{C} .{ }^{\mathrm{f}} \mathrm{EtMgBr}(0.15 \mathrm{mmol})$ was used as the catalyst. ${ }^{\mathrm{g}}$ Initiation was performed at $30^{\circ} \mathrm{C} .{ }^{\mathrm{h}}$ IPA $(1.0 \mathrm{~g}, 7.5 \mathrm{mmol})$ was used. 
(run 4 in Table I) obtained with the EtMgBr-Sp complex are shown in Figure 2. Proton resonances were assigned on the basis of 2D COSY spectrum (Figure 4), comparison of NMR data of model compounds with those of the poly(TPA) and hydrolyzed compounds derived
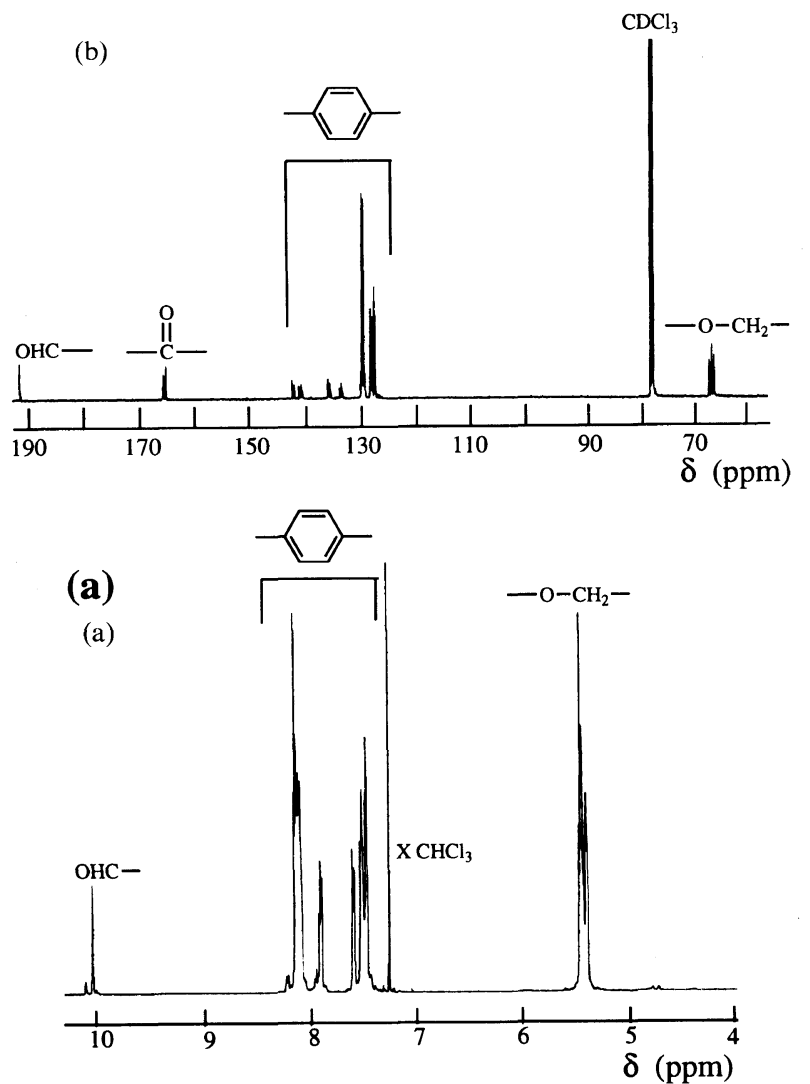

Figure 2. ${ }^{1} \mathrm{H}$ (a) and ${ }^{13} \mathrm{C}$ (b) NMR spectra of poly(TPA) (run 4 in Table I) in $\mathrm{CDCl}_{3}$ at $60^{\circ} \mathrm{C}$ obtained with the $\mathrm{EtMgBr}-\mathrm{Sp}$ complex. from the poly(TPA) in alkaline solution (see below). In the spectra, characteristic peaks due to the ester carbonyl carbons and $\mathrm{O}-\mathrm{CH}_{2}$ carbon and proton resonances appeared at around 166 and $66 \mathrm{ppm}$ in the ${ }^{13} \mathrm{C}$ NMR and $5.4 \mathrm{ppm}$ in the ${ }^{1} \mathrm{H}$ NMR spectrum, respectively, although the spectral patterns were not simple but rather complicated, indicating that the structure of poly(TPA) is not pure poly(oxycarbonyl-1,4-phenylenemethylene) (1), but may be a random copolymer composed of oxycarbonyl-1,4-phenylenemethylene and terephthaloyloxymethylene-1,4-phenylenemethyleneoxy units (2). Clear resonances due to the proton and carbon resonances due to a formyl group appeared at around 10 and $192 \mathrm{ppm}$ in the ${ }^{1} \mathrm{H}$ and ${ }^{13} \mathrm{C}$ NMR spectra, respectively. This suggests that the poly(TPA) obtained with the EtMgBr-Sp complex probably has formyl terminals, while peaks due to other possible end groups such as hydroxymethyl groups were not observed. In the present polymerization, poly- or oligoaldehydes were not detected, since the reaction of benzaldehyde with a catalytic amount of the EtMgBr-Sp complex $(2 \mathrm{~mol} \%)$ in chloroform gave benzyl benzoate almost quantitatively (95\% yield).

Poly(IPA) (run 16 in Table I) gave similar IR and NMR spectra to those of poly(TPA). The polymer showed the absorption at 1720 , and 1274 and $1100 \mathrm{~cm}^{-1}$ due to $\mathrm{C}=\mathrm{O}$ and $\mathrm{C}-\mathrm{O}$ stretchings, respectively in its IR spectrum and characteristic peaks due to the $\mathrm{O}-\mathrm{CH}_{2}$ proton resonances appeared at around at $5.4 \mathrm{ppm}$ in addition to the formyl proton resonances at $c a .10 \mathrm{ppm}$ in the ${ }^{1} \mathrm{H}$ NMR spectrum.

To determine the structure of poly(TPA)s and polymerization mechanism, the poly(TPA) obtained with the EtMgBr-Sp complex (run 4 in Table I) was hydrolyzed with $\mathrm{KOH}$ in ethanol and spectroscopic data including

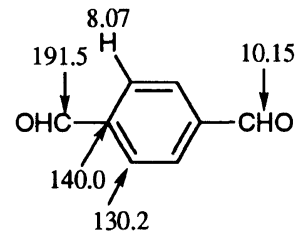

TPA: $m / z 134\left(\mathrm{M}^{+}\right)$<smiles>COC(=O)c1c([13CH3])cc([13CH3])cc1[18OH]</smiles>

3: $\mathrm{m} / z 194\left(\mathrm{M}^{+}\right)$

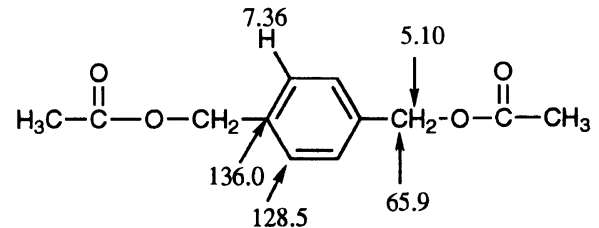

4: $\mathrm{m} / \mathrm{z} 222\left(\mathrm{M}^{+}\right)$

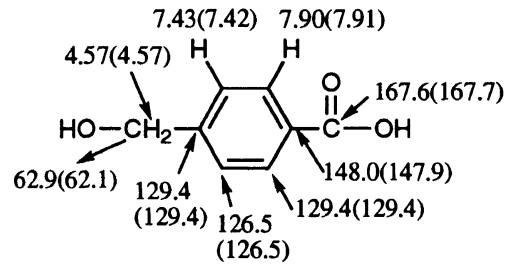

5: $m / z 152\left(\mathbf{M}^{+}\right)(152)$

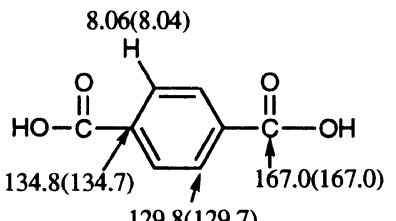

129.8(129.7)

6: $m / z 166\left(\mathrm{M}^{+}\right)(166)$

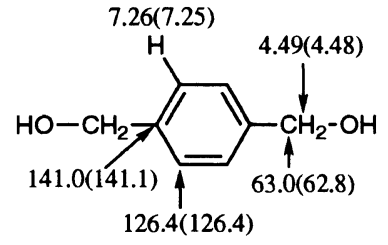

7: $m / z 138\left(\mathrm{M}^{+}\right)(138)$



8: $m / z$ (136)

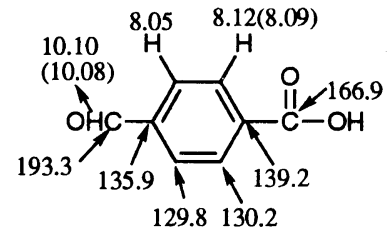

9: $m / z 149\left(\mathbf{M}^{+}\right)(149)$

Figure 3. Spectroscopic data of TPA and model compounds (3-9). Experimental data from hydrolysis of poly(TPA) (run 4 in Table I) obtained with the EtMgBr-Sp complex are shown in parentheses. NMR spectra of TPA, 3, and 4 were measured in $\mathrm{CDCl}_{3}$ and those of $5-9$ were in DMSO- $d_{6}$. NMR data of 8 in $\mathrm{CDCl}_{3}$ was taken from ref 14. 
${ }^{1} \mathrm{H}$ and ${ }^{13} \mathrm{C}$ NMR and mass spectra of the hydrolyzed compounds derived from the poly(TPA) together with those of model compounds (3-9) are shown in Figure 3 . The hydrolyzed products were identified by comparison of the ${ }^{1} \mathrm{H}$ NMR and mass spectral data with those of the authentic samples and were found to be a mixture of 4-(hydroxymethyl)benzoic acid (5), terephthalic acid (6), 1,4-bis(hydroxymethyl)benzene (7), and 4-(hydroxymethyl)benzaldehyde (8), and their molar ratio was roughly estimated to be $4.8: 2: 1: 0.5$ judging from the integral ratio of the corresponding proton resonances in DMSO- $d_{6}$. 4-Carboxybenzaldehyde (9) was hardly detected in the hydrates. These results support the speculation above that the poly(TPA) is not pure poly(oxycarbonyl-1,4-phenylenemethylene) (1), but a random copolymer composed of oxycarbonyl-1,4-phenylenemethylene and terephthaloyloxymethylene-1,4-phenylenemethyleneoxy units (2). However, the above molar ratio of $5-\mathbf{8}$ was not directly correlated with the exact composition of the poly(TPA), since it is well known that two benzaldehyde molecules react to give one benzoic acid molecule and one benzyl alcohol molecule in aqueous alkaline solution (Cannizzaro reaction). ${ }^{16}$ Therefore, portions of 8 and 9 may be converted to 7 and 6 during the alkaline hydrolysis, respectively, and the amount of formyl group and degree of polymerization (DP) of the poly(TPA) could not be determined from the hydrolysis results. In fact, compound $9(0.5 \mathrm{~g})$ yielded $5(34 \%), 6$ $(48 \%)$, and unreacted $9(18 \%)$ under the same conditions in the hydrolysis of the poly(TPA). Excess of 6 may be due to oxidation of 9 during the reaction. Moreover, it was difficult to recover 7 completely with ether from an aqueous solution of 7. A control experiment of the extraction of an aqueous solution of $7\left(0.5 \mathrm{~g} / 15 \mathrm{ml} \mathrm{H} \mathrm{H}_{2} \mathrm{O}\right)$ with ether suggested the recovery of 7 to be $c a .80 \%$ even after three times extraction with ether $(50 \mathrm{ml})$.

For comparison, poly(oxycarbonyl-1,4-phenylenemethylene) (1) was prepared according to the method reported by Pinkus, et al. ${ }^{14}$ As reported in their paper, the obtained polymer was not soluble in common organic solvents including chloroform, THF, DMSO, and acetone (see Experimental). However, they measured the ${ }^{1} \mathrm{H}$ NMR of the polymer in a mixture of DMSO and hexafluoroisopropanol and reported the spectrum; aromatic and methylene protons appeared as broad doublet at 7.5 and $8.0 \mathrm{ppm}$ and broad singlet at $5.4 \mathrm{ppm}$, respectively. These chemical shift values agreed with those assigned in Figures 2(a) and 4.

Figure 4 shows the COSY spectrum of the poly(TPA) obtained with the EtMgBr-Sp complex (run 4 in Table $\mathrm{I})$; a number of cross peaks $(\mathrm{A}-\mathrm{F})$ and diagonal peaks showing no shift correlation $(\mathrm{G}$ and $\mathrm{H})$ were observed in the region of aromatic-aromatic proton resonances. Based on the ${ }^{1} \mathrm{H}$ NMR data of the hydrolyzed compounds derived from the poly(TPA) and those of the model compounds ( $3-9)$, the signals could be tentatively assigned and a possible structure of poly(TPA) is proposed in Figure 5. The aromatic peaks $(\mathrm{G}$ and $\mathrm{H})$ were unambiguously assigned to the proton resonances of $\mathrm{Hf}$ and $\mathrm{He}$, respectively, because the protons are almost

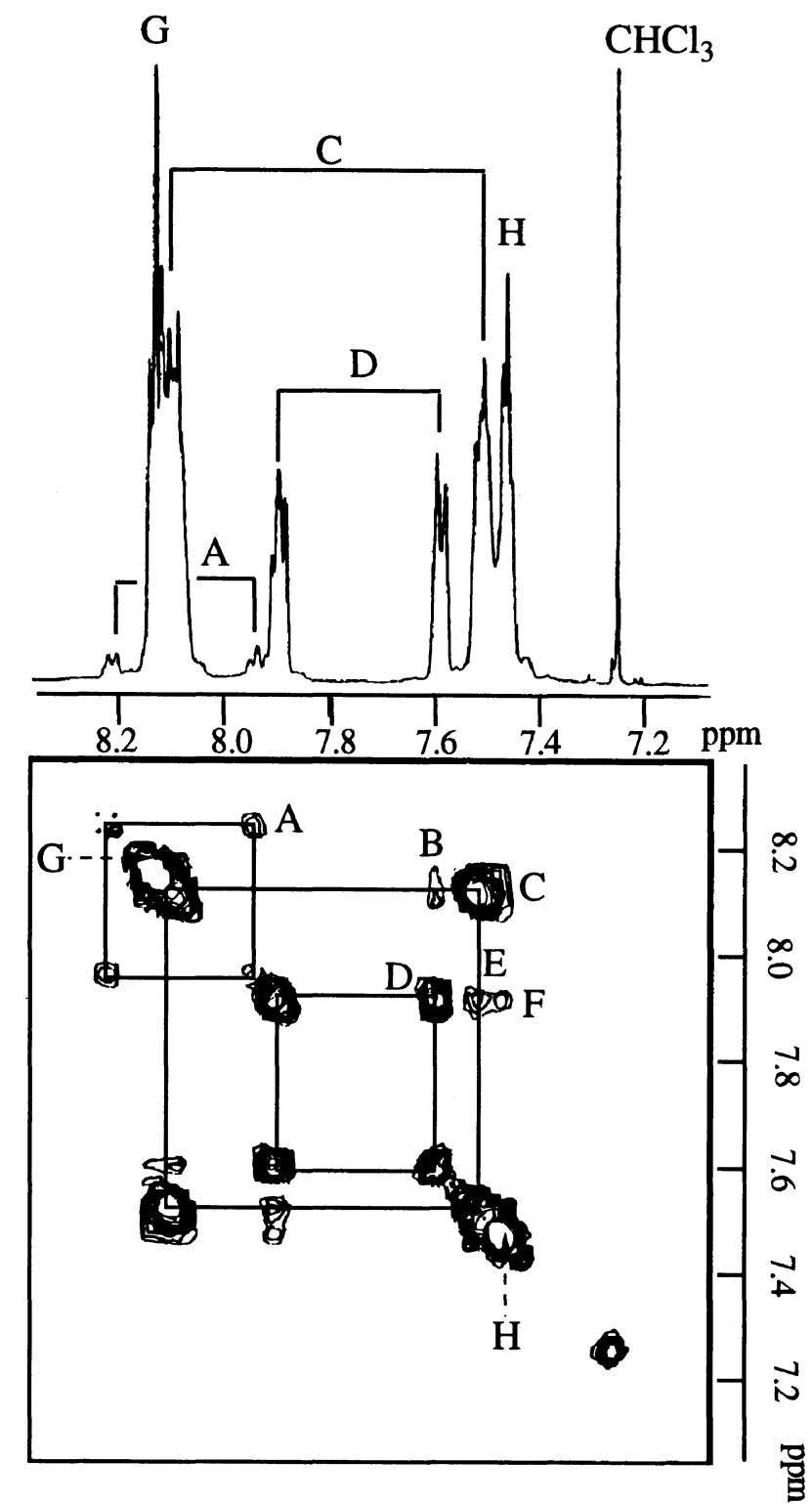

Figure 4. ${ }^{1} \mathrm{H}-{ }^{1} \mathrm{H}$ COSY spectrum of poly(TPA) (run 4 in Table I) in $\mathrm{CDCl}_{3}$ obtained with the $\mathrm{EtMgBr}-\mathrm{Sp}$ complex.



Figure 5. Possible structure of poly(TPA) obtained with the EtMgBr-Sp complex and hydroxymethyl terminal ends (10 and 11$)$. 


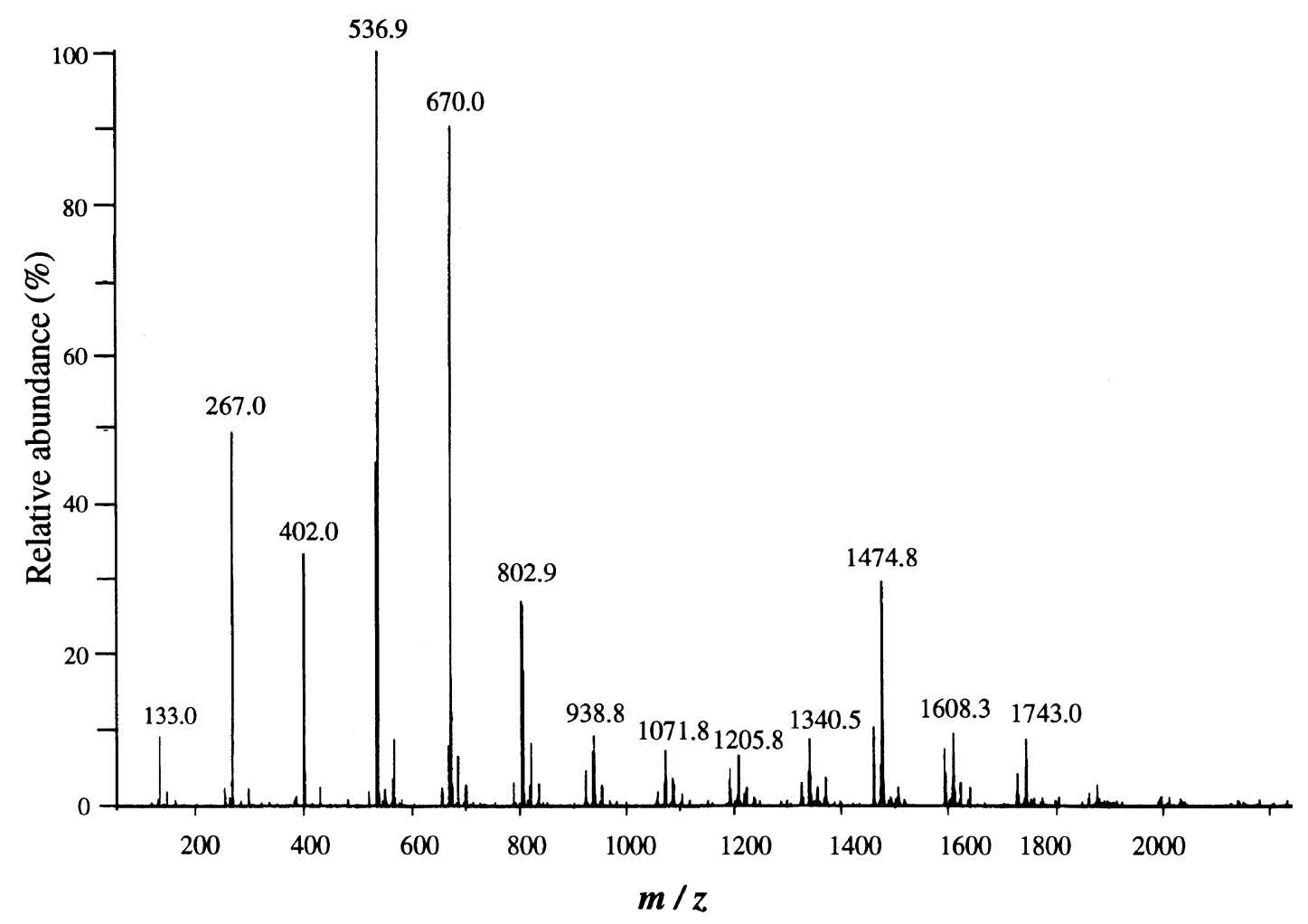

Figure 6. FD mass spectrum of poly(TPA) (run 2 in Table I) obtained with the EtMgBr-Sp complex in $\mathrm{THF}$ at $30^{\circ} \mathrm{C}$.

equivalent, while the cross peaks $\mathrm{A}, \mathrm{C}$, and $\mathrm{D}$ may be correlated between $\mathrm{Ha}$ and $\mathrm{Hb}, \mathrm{Hc}$ and $\mathrm{Hd}$, and $\mathrm{Hg}$ and $\mathrm{Hh}$ proton resonances, respectively. The cross peak B, E, and F could not be assigned at present. The peaks may be derived from lower molecular weight poly(TPA). Other possible terminal ends such as $\mathbf{1 0}$ and $\mathbf{1 1}$ in Figure 5 were not detected in the NMR spectra. The existence of carboxy groups as terminal ends may be excluded according to the mechanism of polymerization (see below).

From the integral ratio of the formyl terminal proton and the aromatic and methylene proton resonances, DP and composition of the poly(TPA) were roughly obtained; $\mathrm{DP}=c a .10$ and $5: 6: 7: 8: 9=2: 1: 1: 1: 0.2$, respectively, assuming that the polymer has formyl terminals at both ends and compositions of 6 and 7 to be at $1: 1$. These results indicate that the poly(TPA) may be a $2: 1$ random copolymer of 1 and 2 units. The above compositions of $\mathbf{5}-\mathbf{8}$ differed from those estimated from the hydrolysis results of poly(TPA) $(5: 6: 7: 8=4.8: 2$ : $1: 0.5)$. This may be ascribed to side reactions such as the Cannizzaro reaction and oxidation of the formyl groups of $\mathbf{8}$ and 9 during the alkaline hydrolysis as mentioned above and difficulty in complete recovery of water soluble 7 by ether extraction from the hydrates in aqueous layer.

Figure 6 shows the FD mass spectrum of the low molecular weight poly(TPA) obtained with the EtMgBrSp complex (run 2 in Table I). The spectrum showed peaks corresponding to the molecular mass of the polymers (2-13 mers) with the possible structure of poly(TPA) having formyl groups at the terminal ends. The main peaks were assigned to oligomers (4 and 5 mers), and higher molecular weight polymers were also detected.
As reported previously for the asymmetric polymerization of 3-PPA and enantioselective Tishchenko reaction of $( \pm)$-2-PPA with the EtMgBr-Sp complex in toluene at $-78^{\circ} \mathrm{C}, \mathrm{EtMgBr}$ is not the real initiator of most molecules, but 3-phenyl- or 2-phenylpropoxymagnesium bromide is a real intermediate and further reacts with 3-PPA or 2-PPA followed by the Tishchenko-type termination again with the aldehydes to afford optically active poly(3-PPA) having an ester terminal at $\omega$-end or 2-phenylpropyl 2-phenylpropanoate as a cyclic mechanism, respectively. ${ }^{9,10}$ Similar cyclic mechanism may also operate for the present reaction system. According to the previously proposed mechanism, ${ }^{9,10}$ the present polyester formation through the Tishchenko reaction may be considered as shown in Scheme 1. Part of the EtMgBr(-)-Sp complex reacts with TPA as a nucleophile to afford 1-(4-formylphenyl)propoxymagnesium bromide, and complex A may be formed by the coordination of TPA. The hydride transfer from an alkoxy group to a carbonyl group of TPA may produce ethyl 4-formylphenyl ketone and 4-formylbenzylalkoxymagnesium bromide in complex B through the Meerwein-PonddorfVerley reduction as reported by Saegusa et al. for the reaction of diethylaluminum sec-butoxide and $n$-butyraldehyde. ${ }^{17}$ This reaction is reversible. Another route to the formation of 4-formylbenzylalkoxymagnesium bromide is an alkoxy group transfer to the carbonyl group of TPA (C), followed by the coordination of TPA (D) and the hydride transfer reaction by the Tishchenko reaction $(\mathrm{E})$. The resulting 4-formylbenzylalkoxymagnesium-(-)-Sp complex (F) must be a real nucleophile and further reacts with TPA followed by the Tishchenkotype termination again with TPA to afford poly(TPA) (Scheme 1(b)). The FD mass spectrum of the methanol soluble fraction of run 4 in Table I showed main peaks 

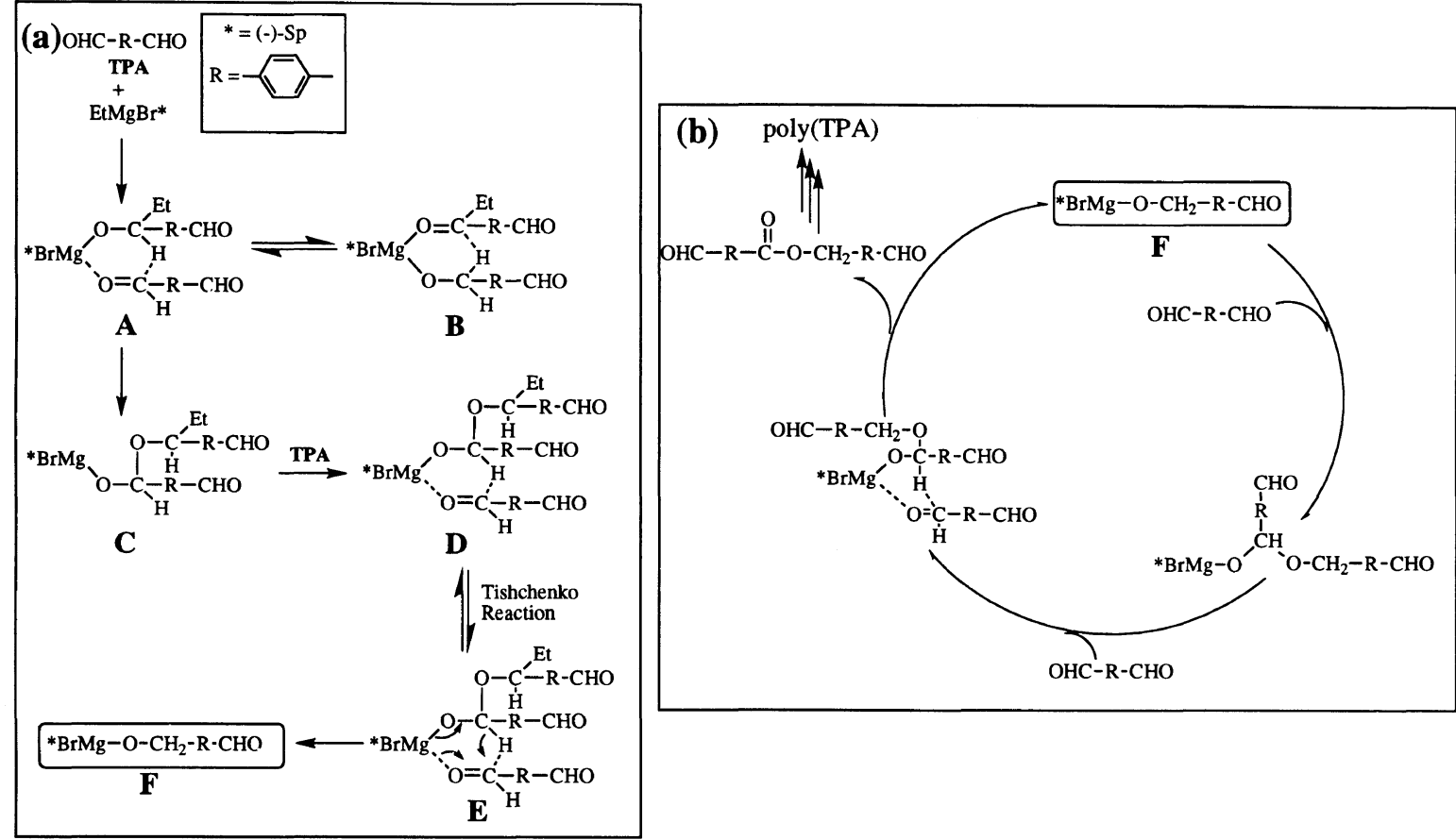

Scheme 1. Mechanism for the polymerization of TPA with the EtMgBr-Sp complex through the Tishchenko reaction: (a) initiation; (b) propagation.

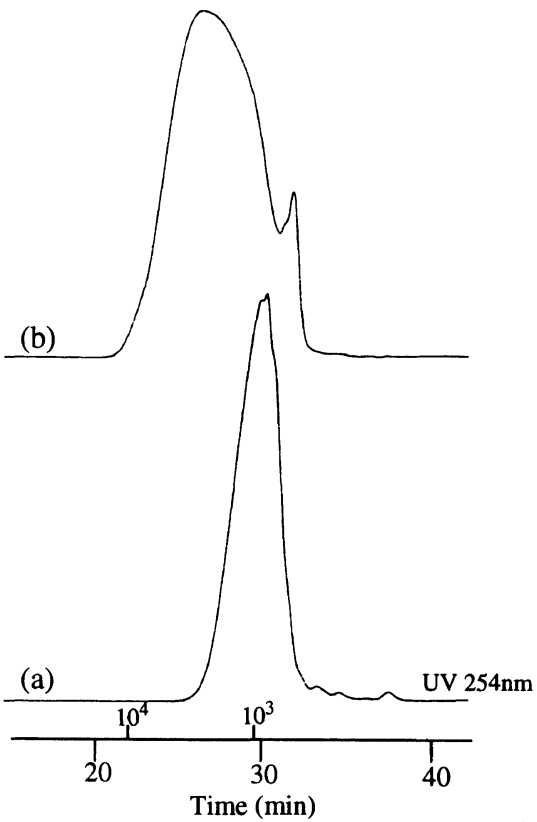

Figure 7. GPC curves of poly(TPA) (a) (run 7 in Table I) obtained with the EtMgBr-Sp complex and polymerized poly(TPA) (b) with the $\mathrm{EtMgBr}-\mathrm{Sp}$ complex in dichloromethane at $30^{\circ} \mathrm{C}$ for $18 \mathrm{~h}$.

of $m / z 133.1,267.2,401.3,535.4$, and 669.0 corresponding to $1-5$ mers. However, other peaks corresponding to the molecular weight of the ketones in $\mathrm{B}$ and $\mathrm{E}$ in Scheme 1 could not be detected probably due to very low concentration.

The complex of bismagnesium alkoxide with (-)sparteine prepared by the reaction of $\mathrm{EtMgBr}$ and 1,4bis(hydroxymethyl)benzene $(7)$ (molar ratio $=2: 1$ ) was used as the catalyst $(2 \mathrm{~mol} \%)$ for the polymerization of TPA in chloroform at $30^{\circ} \mathrm{C}$. The obtained polymer had a similar molecular weigh $\left(M_{n}=1600\right)$ and showed IR and ${ }^{1} \mathrm{H}$ NMR spectral patterns similar to Figures 1 and 2(a). This suggests that the alkoxide-Sp complex ( $F$ in



Figure 8. TG curves of poly(TPA) (a) (run 7 in Table I) obtained with the $\mathrm{EtMgBr}-\mathrm{Sp}$ complex, polymerized poly(TPA) (b), poly(TPP) (c), and poly(oxycarbonyl-1,4-phenylenemethylene) (1) (d).

Scheme 1) is an active specie for ester formation.

According to the mechanism, most poly(TPA) should have formyl terminals at both ends because only a catalytic amount of the compound $\mathrm{F}$ is enough for the Tishchenko reaction in a cyclic mechanism. This indicates that the polymers may be further polymerized with the EtMgBr-Sp complex. To confirm this, the poly(TPA) $\left(M_{n}=2100\right.$, run 7 in Table I) was polymerized with the complex in dichloromethane at $30^{\circ} \mathrm{C}$ for $18 \mathrm{~h}$. Figure 7 demonstrates GPC curves of the original poly(TPA) (a) and the polymer (b) obtained from the polymerization of the original poly(TPA) with the EtMgBr-Sp complex. The top peak moved to higher molecular weight region and $M_{n}$ of the polymer increased to 3900 . These results indicate that poly(TPA)s prepared with the EtMgBr-Sp have reactive formyl groups and can be used as a monomer again.

Figure 8 shows the TGA thermograms of the original 
Table II. Polymerization of TPA with (R)-BIN-Al or Al[OCH( $\left.\left(\mathrm{CH}_{3}\right)_{2}\right]_{3}$ in $\mathrm{CH}_{2} \mathrm{Cl}_{2}$ for $18 \mathrm{~h}^{\mathrm{a}}$

\begin{tabular}{clcccc}
\hline Run & \multicolumn{1}{c}{ Catalyst } & Temp $/{ }^{\circ} \mathrm{C}$ & Yield $/ \%{ }^{\mathrm{b}}$ & $\bar{M}_{n} \times 10^{-3^{\mathrm{c}}}$ & $\bar{M}_{w} / \bar{M}_{n}{ }^{\mathrm{c}}$ \\
\hline 1 & $(R)-\mathrm{BIN}-\mathrm{Al}$ & 30 & 83.3 & 3.9 & 1.42 \\
2 & & 0 & 0 & - & - \\
3 & $\mathrm{Al}\left[\mathrm{OCH}\left(\mathrm{CH}_{3}\right)_{2}\right]_{3}$ & 30 & 68.1 & - & 1.6 \\
4 & & 0 & 0 & - & - \\
\hline
\end{tabular}

${ }^{\mathrm{a}} \mathrm{TPA}(1.0 \mathrm{~g}, 7.5 \mathrm{mmol}), \mathrm{CH}_{2} \mathrm{Cl}_{2} 10 \mathrm{ml},[\mathrm{TPA}] /[$ catalyst $]=50 .{ }^{\mathrm{b}} \mathrm{MeOH}$-insoluble fraction. ${ }^{\mathrm{c}}$ Estimated by GPC (polystyrene standards).

poly(TPA) (run 7 in Table I) and polymerized poly(TPA) with the EtMgBr-Sp complex and model polyesters, poly(terephthaloyloxymethylene-1,4-phenylenemethyleneoxy) (poly(TPP)) and poly(oxycarbonyl-1,4-phenylenemethylene) (1). The thermal properties including thermal decomposition temperatures were dependent on the main chain structures of the polyesters. Poly(TPP) and 1 were more thermally stable than poly(TPA) and weight loss of the polyesters occurred at around $350^{\circ} \mathrm{C}$ in air. On the other hand, the weight loss of the original poly(TPA) began at around $210^{\circ} \mathrm{C}$ and the TGA thermogram of the polymerized poly(TPA) showed a slightly different curve.

\section{Polymerization of TPA with Aluminum Alkoxides}

Table II shows the results of polymerization of TPA with aluminum isopropoxide and $(R)-(+)-1,1^{\prime}$-bi-naphthoxymethylaluminum $((R)-\mathrm{BIN}-\mathrm{Al})$ in dichloromethane at 0 or $30^{\circ} \mathrm{C}$. Mitin et al. ${ }^{6}$ and later, Sweeny ${ }^{7}$ reported that aluminum isopropoxide did not polymerize TPA, although aluminum ethoxide and triisopropylaluminum were effective catalysts for the polymerization of TPA through the Tishchenko reaction. However, the present results clearly show that aluminum isopropoxide is also an effective catalyst as well as $(R)-\mathrm{BIN}-\mathrm{Al}$ as shown in Table II, though at $0^{\circ} \mathrm{C}$ no polymer was obtained with the catalysts. The poly(TPA)s obtained with the catalysts showed IR and ${ }^{1} \mathrm{H}$ NMR spectra similar to those of poly(TPA)s prepared with the EtMgBr-Sp complex, indicating that the polyesters consisted of oxycarbonyl1,4-phenylenemethylene (1) and terephthaloyloxymethylene-1,4-phenylenemethyleneoxy (4-xylyleneterephthalate) units (2) in analogy with poly(TPA)s prepared with the EtMgBr-Sp complex.

Acknowledgment. The present work was supported in part by Grant-in-Aid for Scientific Research on Priority Areas, "New Polymers and Their Nano-Organized Systems" (No. 277/08246103), from the Ministry of Education, Science, Sports, and Culture of Japan.

\section{REFERENCES AND NOTES}

1. V. E. Tishchenko, J. Russ. Phys. Chem. Soc., 38, 335 (1906).

2. (a) M. Yamashita, Y. Watanabe, T. Mitsudo, and Y. Takegami, Bull. Chem. Soc. Jpn., 49, 3597 (1976). (b) S. Komiya, S. Taneichi, A. Yamamoto, and T. Yamamoto, Bull. Chem. Soc. Jpn., 53, 673 (1980).

3. (a) T. Saegusa, K. Hirota, E. Hirasawa, and H. Fujii, Bull. Chem. Soc. Jpn., 40, 967 (1967). (b) P. R. Stapp, J. Org. Chem., 38, 1433 (1973). (c) Y. Ogata, A. Kawasaki, and I. Kishi, Tetrahedron, 23, 825 (1967).

4. (a) S. Y. Onozawa, T. Sakakura, and M. Tanaka, Chem. Lett., 531 (1994). (b) K. Yokoo, N. Mine, H. Taniguchi, and Y. Fujiwara, J. Organometal. Chem., 279, 19 (1985).

5. (a) H. Horino, T. Ito, and A. Yamamoto, Chem. Lett., 17 (1978). (b) T. Ito, H. Horino, Y. Koshiro, and A. Yamamoto, Bull. Chem. Soc. Jpn., 55, 504 (1982).

6. Y. V. Mitin, N. Sazanov, and G. P. Vlasov, Vysokomol. Soedin., 2, 716 (1960).

7. W. Sweeny, J. Appl. Polym. Sci., 7, 1983 (1963).

8. T. Kimishima, I. Yamaguchi, K. Osakada, and T. Yamamoto, Polym. Prepr. Jpn., 44, 987 (1995).

9. S. H. Choi, E. Yashima, and Y. Okamoto, Macromolecules, 29, 1880 (1996).

10. S. H. Choi, E. Yashima, and Y. Okamoto, Enantiomer, in press.

11. (a) P. Beak, S. T. Kerrick, S. Wu, and J. Chu, J. Am. Chem. Soc., 116, 3231 (1994). (b) I. Hoppe, M. Marsch, K. Harms, G. Boche, and D. Hoppe, Angew. Chem., Int. Ed. Engl., 34, 2158 (1995). (c) S. Wu, S. Lee, and P. Beak, J. Am. Chem. Soc., 118, 715 (1996) and references cited therein.

12. (a) Y. Okamoto and T. Nakano, Chem. Rev., 94, 349 (1994). (b) T. Nakano, Y. Okamoto, and K. Hatada, J. Am. Chem. Soc., 114, 1318 (1992).

13. (a) Y. Okamoto, K. Ohta, and H. Yuki, Macromolecules, 11, 724 (1978). (b) Y. Okamoto, K. Suzuki, T. Kitayama, H. Yuki, H. Kageyama, K. Miki, N. Tanaka, and N. Kasai, J. Am. Chem. Soc., 104, 4618 (1982).

14. (a) A. G. Pinkus, R. Subramanyan, and R. Hariharan, J. Macromol. Sci., Pure Appl. Chem., A29, 1031 (1992). (b) A. G. Pinkus and R. Hariharan, J. Macromol. Sci., Rev. Macromol. Chem. Phys., C33, 259 (1993).

15. W. S. Emerson and R. A. Heimsch, J. Am. Chem. Soc., 72, 5152 (1950).

16. S. F. Pine, "Organic Chemistry," Fifth Ed., McGraw-Hill, New York, N.Y., 1987, p 236.

17. T. Saegusa, K. Hirota, E. Hirasaka, and H. Fujii, Bull. Chem. Soc. Jpn., 40, 967 (1967). 